\begin{tabular}{|c|c|}
\hline Title & In V ivo Transgene Expression in the Pancreas by the Intraductal Injection of Naked Plasmid DNA \\
\hline Author(s) & Y amada, Y uma; Tabata, Mai; A be, Jiro; Nomura, Masatoshi; Harashima, Hidey oshi \\
\hline Citation & $\begin{array}{l}\text { Journal of Pharmaceutical Sciences, 107(2), 647-653 } \\
\text { https://doi.org/10.1016/א.xphs.2017.09.021 }\end{array}$ \\
\hline Issue Date & 201802 \\
\hline Doc URL & http:/hdl .handle.net/2115/72700 \\
\hline Rights & $\begin{array}{l}\text { @2018. This manuscript version is made avail able under the CC-BY - NC-ND } 4.0 \text { license } \\
\text { http://creativecommons.org/icenses/by-nc-nd/4.0/ }\end{array}$ \\
\hline Rights(URL) & http://creativecommons.org/icenses/by-nc-nd/4.0/ \\
\hline Type & article (author version) \\
\hline File Information & WoS_82241_YYamada.pdf \\
\hline
\end{tabular}

Instructions for use 


\section{In vivo transgene expression in the pancreas by the intraductal injection of naked plasmid DNA.}

Yuma Yamada ${ }^{1,4}$, Mai Tabata ${ }^{1,4}$, Jiro Abe ${ }^{1,2}$, Masatoshi Nomura ${ }^{3}$ and Hideyoshi Harashima ${ }^{1, *}$

${ }^{1}$ Laboratory for Molecular Design of Pharmaceutics, Faculty of Pharmaceutical Sciences, Hokkaido University, Sapporo, Japan

${ }^{2}$ Department of Pediatrics, Hokkaido University Hospital, Kita-15, Nishi-7, Kita-ku, Sapporo 060-8638, Japan

${ }^{3}$ Department of Endocrine and Metabolic Diseases / Diabetes Mellitus, Kyushu University Hospital, 31-1 Maidashi, Higashi-ku, Fukuoka 812-8582, Japan

${ }^{4}$ These authors contributed equally as first author

*To whom correspondence should be addressed:

Tel +81-11-706-3919 Fax +81-11-706-3734 E-mail harasima@pharm.hokudai.ac.jp

\section{Keywords}

DNA delivery; Drug delivery systems; Gene delivery; Gene therapy; Toxicity. 


\begin{abstract}
.
Patients with type I diabetes, which is caused by the destruction of pancreatic islets, now require regular therapeutic injections of insulin. The use of transgene therapy represents an alternate and potent strategy for the treatment of type I diabetes. However, only a limited number of studies regarding in vivo gene delivery targeting the pancreas and islets have been reported. Here, we report on the possibility of in vivo transgene expression in the pancreas by the intraductal injection of naked plasmid DNA (pDNA). Gene expression activities were detected in the pancreas of mice after the injection of naked pDNA encoding luciferase into the common bile duct. We then investigated the effects of injection dose, volume and speed on gene delivery, and determined the optimal conditions for the delivery of pDNA to the pancreas. Exogenous luciferase mRNA was detected in the pancreatic islets by reverse transcription PCR analysis. Moreover, no injury was detected in the liver, the common bile duct, or the pancreas over time after the injection. These findings indicate that the intraductal injection of naked pDNA promises to be a useful technique for in vivo gene delivery targeted to pancreatic tissue and islets.
\end{abstract}




\section{INTRODUCTION}

Pancreatic $\beta$ cells constitute the majority of cells in pancreatic islets. They function to maintain serum glucose levels by secreting insulin in response to fluctuations in serum glucose levels. Patients with type I diabetes, which is caused by islet dysfunction, typically require an external source of insulin. Mutations in genes related to pancreatic $\beta$ cell function have been associated with certain types of diabetes mellitus ${ }^{1,2}$. These genes are associated with important pancreatic $\beta$ cell functions, including the production and secretion of insulin. The activation of islets by a transgene represents a potentially viable therapy for many patients who suffer from diabetes mellitus. To achieve such a goal, technology for delivering therapeutic genes to pancreatic islets is needed.

However, our knowledge regarding in vivo gene delivery targeting the pancreas and islets is currently very limited ${ }^{3-6}$, although many studies regarding in vivo gene delivery targeting other tissues including liver have been reported ${ }^{7-10}$. Even though this is a serious situation, Rehman et al. reported that the adeno associated virus (AAV) 8-mediated gene transfer of interleukin-4 to pancreatic $\beta$ cells prevents the onset of diabetes in non-obese diabetic mice ${ }^{5}$. In this study, the authors succeeded in achieving selective gene expression in pancreatic $\beta$ cells by the intraperitoneal injection of AAV8 containing a murine insulin promoter. In this case, although selective gene expression in pancreatic $\beta$ cells was achieved, as evidenced by the finding that AAV8 was distributed throughout the body, toxicity associated with the transfer of AAV to other organs would be unclear. Thus, achieving a safe, simple and efficient method continues to be a goal, and approaches from various fields are required.

In this study, we first investigated the targeted delivery of pDNA to the pancreas of mice via hydrodynamic injection. Hydrodynamic injection, in which a large volume of naked pDNA is rapidly injected into the tail vein of the mouse, has been frequently used as an efficient in vivo nuclear gene transfer method for delivering naked pDNA to hepatocytes ${ }^{11-13}$. Liu et al. ${ }^{14}$ reported that this method could also achieve transgene expression in the kidney, spleen, lung and heart, although these transfection 
efficiencies were lower than that in the liver. Thus, we hypothesized that hydrodynamic injection might be a candidate for the targeted delivery of a gene to the pancreas.

We next validated the occurrence of in vivo transgene expression in the pancreas by the intraductal injection of naked pDNA. It has been reported that gene delivery by hydrodynamic injection transiently enhances membrane permeability, which would contribute to the introduction of pDNA to the cellular membrane ${ }^{15}$. Thus, we expected that the hydrodynamic force caused by the intraductal injection could result in selective targeting to the pancreas. Gene expression activities were measured in the pancreas and other tissues by the intraductal injection of naked pDNA encoding luciferase. We also performed reverse transcription PCR analyses to detect exogenous luciferase mRNA in pancreatic islets. Moreover, injuries to the liver, the common bile duct and the pancreas were evaluated over time after the injection. 


\section{MATERIALS AND METHODS}

\section{Materials}

The pcDNA3.1 (+)-luc plasmid was constructed by inserting the firefly luciferase gene (Hind IIIXba I fragment) of the pGL3-Control plasmid (Promega, Madison, WI, USA) into the pcDNA3.1 (+) plasmid (Invitrogen, Carlsbad, CA, USA) pretreated with the same restriction enzymes. The luciferase gene in the pDNA is expressed under the control of the cytomegalovirus promoter. The pDNA was purified using an Endofree Plasmid Giga Kit (Qiagen GmbH, Hilden, Germany). Oligonucleotides for the primers for firefly luciferase (forward: 5'-TCAAAGAGGCGAACTGTGTG-3', reverse: 5'TCGCGGTTGTTACTTGACTG-3') and 18s rRNA (forward: 5'- GGTAACCCGTTGAACCCCAT-3', reverse: 5'- CAACGCAAGCTTATGTCCCG-3') were purchased from Sigma Genosys Japan (Ishikari, Japan) in purified form. Type IV collagenase was purchased from Worthington Biochemical Corporation (Lakewood, NJ, USA). All other chemicals used were commercially available reagent-grade products.

\section{Experimental animals}

Female ICR mice (5-6 weeks old) were purchased from the Sankyo Labo Service (Sapporo, Japan). All animal protocols were approved by the institutional animal care and research advisory committee at the Faculty of Pharmaceutical Sciences, Hokkaido University, Sapporo, Japan (date: 22 March 2013, registration No. 13-0062).

\section{Hydrodynamic injection}

Hydrodynamic tail vein (HTV) injections were performed, as previously described ${ }^{16}$. Briefly, 2 $\mathrm{mL}$ of saline containing pDNA was injected into the tail veins of mice within a period of $3 \mathrm{sec}$. For the experiment shown in Figure 1, $50 \mu \mathrm{g}$ of pDNA was injected.

\section{Intraductal injection}

Mice were anesthetized with isoflurane, and an incision was then made in the abdomen to expose the common bile duct. Prior to each pDNA injection, the sphincter of Oddi was clamped to restrict the flow of the injected solution into the duodenum, as shown in Figure 2a. A 27-gauge needle was inserted into the common bile duct, and the naked pDNA suspension $(50 \mu \mathrm{L})$ containing $0.1-50 \mu \mathrm{g}$ pDNA was then injected from the common bile duct within a period of $5 \mathrm{sec}$. After the injection, the opening of the duct was sealed with medical adhesive and the incision site sutured. We also injected a saline solution of 
$5 \%(\mathrm{w} / \mathrm{v})$ trypan blue in order to observe the distribution of the injected solution in the pancreas, as shown in Figure 2b.

\section{Luciferase assay}

After the injection of the pDNA coding luciferase gene, the mice were sacrificed and tissues including pancreas, liver, spleen, kidney, lung, heart or small intestine were harvested. Each of the tissue samples was homogenized in lysis buffer (100 mM Tris-HCl, 2 mM EDTA, 0.1\% Triton X-100, pH 7.8) using Micro Smash ${ }^{\mathrm{TM}}$ (Tomy seiko co., Ltd., Tokyo, Japan). After centrifugation $\left(4^{\circ} \mathrm{C}, 9,000 \mathrm{~g}, 10 \mathrm{~min}\right)$, a $20 \mu \mathrm{L}$ aliquot of the supernatant was collected and used for luciferase assay with a Luciferase Assay System (Promega, Madison, WI, USA). Protein concentrations were determined with a BCA protein assay kit (Pierce, Rockford, IL, USA). Luciferase activities are expressed as relative light units (RLU) per mg of protein.

\section{Isolation of the pancreatic islets}

Mice were sacrificed and the common bile duct exposed. The sphincter of Oddi was clamped and a 23-27-gauge needle was inserted into the common bile duct. A 7-8 $\mathrm{mL}$ aliquot of a type IV collagenase solution $(2 \mathrm{mg} / \mathrm{mL})$ was injected and the pancreas was then harvested and incubated at $37^{\circ} \mathrm{C}$ for $13 \mathrm{~min}$. The tissue was homogenized with a 14-gauge needle and washed three times with $10 \mathrm{~mL}$ PBS (-). The tissue was suspended in a mixture of $4 \mathrm{~mL}$ HISTOPAQUE-10771 and $4 \mathrm{~mL}$ HISTOPAQUE-11191 (Sigma-Aldrich, St. Louis, MO, USA). Layers of $10 \mathrm{~mL}$ HISTOPAQUE-10771 and $10 \mathrm{~mL}$ PBS (-) were added and centrifuged at $700 \mathrm{~g}$ for $20 \mathrm{~min}$ at $4^{\circ} \mathrm{C}$. The islets present on in the interface between HISTOPAQUE-10771 and PBS (-) were collected with a 14-gauge needle. The purity of the islets was confirmed by microscopic observations.

\section{Detection of luciferase mRNA in pancreas and islets}

Total RNA was extracted from $20 \mathrm{mg}$ of pancreas tissue or 150-200 islets with TRIzol reagent (Life Technologies, Gaithersburg, MD, USA) and reverse transcribed using a High capacity cDNA reverse transcription kit (Life Technologies) according to manufacturer's protocol. The resulting cDNA was analyzed by PCR, as described below. A mixture containing template cDNA, Standard Taq Reaction Buffer (NEB, Hitchin, UK), $0.2 \mathrm{mM}$ dNTPs, $0.2 \mu \mathrm{M}$ forward or reverse primers and Taq DNA polymerase (NEB) in a total volume of $25 \mu \mathrm{L}$ was prepared for PCR analysis. The mixture was first incubated at $95^{\circ} \mathrm{C}$ for $2 \mathrm{~min}$, then subjected to 30 cycles of $95^{\circ} \mathrm{C}$ for $30 \mathrm{sec}, 60^{\circ} \mathrm{C}$ for $30 \mathrm{sec}$ and $72^{\circ} \mathrm{C}$ for $45 \mathrm{sec}$, and finally to $72^{\circ} \mathrm{C}$ for $5 \mathrm{~min}$. Each $9 \mu \mathrm{L}$ of PCR products were used for electrophoresis in $2 \%$ agarose gel in TBE 
(89 mM Tris-HCl, $89 \mathrm{mM}$ boric acid, 2 mM EDTA). The bands were visualized by UV after staining with GelRed Nucleic Acid Stain (Biotium, Hayward, CA, USA).

\section{Evaluation of injury}

Blood was collected from the tail vein of mice at 1,2 and 6 days after pDNA administration via the intraductal injection of $1 \mu \mathrm{g}$ pDNA in $50 \mu \mathrm{L}$ saline within a period of $5 \mathrm{sec}$. Serum was obtained by centrifugation at $1,200 \mathrm{~g}$ for $15 \mathrm{~min}$ at $25^{\circ} \mathrm{C}$. ALT (liver injury marker), total bilirubin (injury makers of common bile duct and liver), amylase (pancreas injury maker) and lipase (pancreas injury maker) concentrations was measured by the Oriental Yeast Co., Ltd. (Shiga, Japan). Body weights of the mice were also measured.

Statistical analysis. Data are expressed as the mean \pm S.D. for the indicated number of experiments. For multiple comparisons, one way ANOVA followed by Bonferroni test (Figures 1, 3b) or SNK test (Figure 4) was performed. $p<0.05$ was considered to be statistically significant. 


\section{RESULTS}

\section{Gene delivery by HTV injection and evaluation of transgene expression in various tissues.}

We first investigated the targeted delivery of pDNA to the pancreas of mice via hydrodynamic injection. Liu et al reported that this method could also achieve transgene expression in the kidney, spleen, lung and heart, although the transfection efficiencies in these tissues were lower than that in the liver ${ }^{14}$. Thus, we hypothesized that hydrodynamic injection might be used for the targeted delivery of gene to the pancreas.

In this experiment, $50 \mu \mathrm{g}$ of a pDNA coding luciferase was administered to the tail vein of mice via HTV injection, and the mice were sacrificed at $8 \mathrm{hr}$ post injection. Basically, suspensions of naked pDNA $(2 \mathrm{~mL})$ were injected into the tail vein within a period of $3 \mathrm{sec}$. At $8 \mathrm{hr}$ postinjection, the mice were sacrificed, the tissues including liver, spleen, kidney, lung, heart, pancreas and small intestine were harvested, and luciferase activities were measured (Figure 1). The highest luciferase activity was found in the liver (more than $10^{8} \mathrm{RLU} / \mathrm{mg}$ protein), and less than $10^{6} \mathrm{RLU} / \mathrm{mg}$ protein of luciferase activities was detected in other tissues. Expression in the pancreas was several orders of magnitude lower, and the value was $\sim 10^{4} \mathrm{RLU} / \mathrm{mg}$ of protein.

\section{Establishing pDNA delivery by intraductal injection, and investigations of the pancreas and various tissues.}

Although the detailed mechanism of gene delivery by hydrodynamic injection is not known with certainty, it has been reported that a transient enhancement in membrane permeability would contribute to the introduction of pDNA into the cellular membrane ${ }^{15}$. Based on this possibility, we concluded that hydrodynamic force via intraductal injection might result in selective targeting to the pancreas. Thus, we attempted gene delivery to the pancreas by intraductal injection, and observed the distribution of the injected material. The common bile duct connects the duodenum and the liver, and branches to the main pancreatic duct on its way before reaching the pancreas. Therefore, by clamping the common bile duct 
and the duodenum base (the sphincter of Oddi), a needle could be inserted from the liver side to permit the drugs to be selectively administered to the pancreas (Figure 2a). When a trypan blue solution was injected via intraductal injection, we observed blue signals in the pancreas (Figure 2b), suggesting that this injection route can, in fact, deliver drugs to the pancreas.

We next investigated gene expression in the pancreas and various tissues following the intraductal injection of naked pDNA. Various amounts of pDNA encoding luciferase $(0.1,1,12.5$ or $50 \mu \mathrm{g})$ were injected through the common bile duct. The pancreas was harvested at $24 \mathrm{hr}$ after injection, and the luciferase activities were determined. The highest luciferase activity was found in the pancreas (about $10^{7}$ RLU/mg protein), and its activity was saturated at a dosage of $1 \mu \mathrm{g}$ (Figure 3a). Moreover, we compared gene expression among the liver, spleen, kidney, lung, heart, pancreas and small intestine. The highest luciferase activity was found in the pancreas (about $10^{7} \mathrm{RLU} / \mathrm{mg}$ protein) and less than $10^{4} \mathrm{RLU} / \mathrm{mg}$ of protein with luciferase activity was detected in other tissues (Figure 3b). The results suggest that the intarductal injection of naked plasmid DNA can be useful for transgene expression in the pancreas.

\section{Effects of injection volume and speed on pancreas delivery by intraductal injection of pDNA.}

To determine the optimal conditions for delivering pDNA to the pancreas by intraductal injection, we investigated the effects of injection volume and time on pancreas delivery by means of a luciferase assay (Figure 4). The highest level to the pancreas was found when an injection volume of $50 \mu \mathrm{L}$ containing pDNA was administered (Figure 4a). The rate of administration for producing the highest luciferase activity was found to be within a period of $5 \mathrm{sec}$, moreover, the activity was low enough to be administered over time (Figure 4b). Based on these results, we conclude that the injection of pDNA in 50 $\mu \mathrm{L}$ of solution in $5 \mathrm{sec}$ was the optimal condition for the delivery of pDNA to the pancreas using intraductal injection, and this protocol was followed in all subsequent experiments.

\section{Validation of gene delivery to pancreatic islets via intraductal injection.}


To validate that intraductal injection could be used to deliver naked pDNA to pancreatic islets, we measured luciferase mRNA in pancreatic islets after the intraductal injection of naked pDNA coding luciferase. A schematic diagram showing the isolation of islets from the pancreas is shown in Figure 5a. Briefly, the sphincter of Oddi was clamped and a large volume of a type IV collagenase solution was injected (1), the pancreas was then harvested and incubated at $37^{\circ} \mathrm{C}(2)$, the tissue was homogenized with a 14-gauge needle (3), and the islets and exocrine cells were separated by sucrose density-gradient centrifugation (4). We observed that the purity of the obtained islets was high and that their structures were intact (Figure 5b). Figure 5c shows agarose gel electrophoresis data used to detect luciferase mRNA in the islets. Total RNA was extracted from the islets at $24 \mathrm{hr}$ after the injection of control pDNA nonencoding luciferase (lane 1) and pDNA encoding luciferase (lanes 2, 3), and RT-PCR was performed to obtain the PCR products derived from luciferase mRNA (exogenous pDNA) and 18srRNA (endogenous RNA). A band corresponding to luciferase mRNA was observed in the case of naked pDNA encoding luciferase, (lane2), whereas the injection of a control pDNA showed no luciferase mRNA-band (lane1). These results suggest that the presence of exogenous mRNA could be determined by RT-PCR assays under these conditions, although the amounts of pDNA cannot be determined using this methodology.

We confirmed the absence of contaminating DNA when this RT-PCR assay was performed. Gel images of the RT-PCR detection showed that the target DNA bands appeared in the case of reverse transcription $(\mathrm{RT}+)($ lane 2$)$ and were not observed in the absence of reverse transcription (RT-) (lane 3 ). These results indicate that the DNase I treatment procedure during the RT-PCR assay was appropriately performed. The findings suggest that pDNA encoding luciferase was transcribed inside the pancreas islets.

\section{Evaluation of injury following intraductal injection.}

Serum was collected 1, 2, 6 days after pDNA administration via the intraductal injection of $1 \mu \mathrm{g}$ pDNA in $50 \mu \mathrm{L}$ saline within a period of $5 \mathrm{sec}$. The concentrations of ALT (liver injury maker), total bilirubin (common bile duct and liver injury maker), and amylase and lipase, which are markers of a 
pancreas injury, were then measured (Figure 6a-d). In this experiment, we compared the values among mice that received pDNA by intraductal injection (triangles), sham treated mice which had received no injection although surgery was performed (squares), and non-treated mice (circles).

As shown in Figure 6a, the ALT values for the mice that received pDNA by intraductal injection (triangles) were higher than the corresponding values for the non-treated mice (circles) at an early stage, however the values reached comparable levels at 6 days after the injection. In the case of total bilirubin (a marker of common bile duct and liver injury), the value for the mice that received pDNA by intraductal injection (triangles) was higher than that of non-treated mice (circles) at 1 day, however the values reached comparable levels at 2 days after the injection (Figure 6b). When markers of pancreas injury were measured, the levels of amylase and lipase of the mice that received pDNA by intraductal injection (triangles) were higher than that of non-treated mice (circles) at 1 day, however the values reached comparable levels at 2 days after the injection (Figures 6c, 6d). At an early stage, total bilirubin, amylase and lipase levels were increased in the case of sham treated mice (squares in Figures $6 b-d$ ). We also monitored changes in body weight (Figure 6e) but no significant difference was found among the three groups. 


\section{DISCUSSION}

We report herein on the successful in vivo transgene expression in the pancreas of mice by the intraductal injection of naked pDNA (Figure 3a). Transgene expression was the highest in the pancreas and much lower in other tissues, including the liver, spleen, kidney, lung, heart and small intestine (Figure 3b). These results suggest that the intraductal injection of naked pDNA can be useful for achieving transgene expression in the pancreas. Wang et al. reported that the intraductal delivery of AAV6 (a virus vector) resulted in efficient pancreatic transgene expression ${ }^{6}$, but the intraductal delivery of naked pDNA without a vector for achieving pancreatic transgene expression has not been previously evaluated. Moreover, we also report on a detailed investigation of injuries with respect to the liver, common bile duct and pancreas for the first time. Prior thinking was that inserting a needle from the bile duct would cause significant damage when intraductal delivery was performed (Figure 6).

The results for evaluating injuries showed that the concentrations of ALT (a marker of liver injury), total bilirubin (a marker of injury to the common bile duct and liver), and amylase and lipase (marker of a pancreas injury) were higher than that of non-treated mice at one day after the intraductal injection of pDNA (triangles in Figures 6a-d). The conditions for evaluating injuries were the conditions where the gene expression was the highest, and the intraductal injection of $1 \mu \mathrm{g}$ pDNA in $50 \mu \mathrm{L}$ saline was done within a period of $5 \mathrm{sec}$. It is usually difficult for naked pDNA alone to penetrate the cell membrane from the viewpoint of size and hydrophilicity. Given that gene expression activity was lowered when the administration volume and rate were lowered (Figure 4), we conclude that the gene expression resulting from the intraductal injection of naked pDNA was due to a transient enhancement in cellular membrane permeability, which would increase the amount of pDNA introduced into the cellular membrane, as in the case of the hydrodynamics injection method. As a result, the liver, common bile duct and pancreas might be damaged and be observed as a toxic situation, because a large volume of solution flowed into these tissues within a short time during administration via the bile duct. 
On the other hand, high concentrations of amylase / lipase and bilirubin were also observed in the sham treated mice that had not received an injection of pDNA, but had been subjected to the surgical procedure (squares in Figures 6b-d). This result prompted us to consider another possibility in which the insertion of a needle into the common bile duct might have caused injury to the common bile duct and the pancreas. In the optimal protocol of intraductal injection used in this study, after injection, the opening where the needle had been inserted was sealed with a medical adhesive. At the preliminary trial stage, when intraductal injection was conducted without this operation, numerous mice died within 2 days. This fact strongly suggests that the leakage of bile and enzymes from the opening in the bile duct may have caused injury to the surrounding tissues. Sealing the insertion opening of the bile duct with a medical adhesive suppressed these toxicities, and the survival of all of the mice was greatly improved. Actually, the serum concentrations of amylase and lipase reached the same level as the non-treated mice at 2 days after the injection (Figures $6 \mathrm{c}-\mathrm{d}$ ). Collectively, we speculate that the lethal pancreatic disorder observed at the time of intraductal injection was likely caused by the opening where the needle had been inserted in the bile duct. We also confirmed that this damage can be prevented by an appropriate treatment, such as the use of a medical adhesive. While toxicology studies were not carried out beyond the time at which significant adaptive immune responses would occur, this is an important issue. Investigating the influence of intraductal injection on contributions of adaptive immune mediated toxicity represents an important subject for future investigations.

Endoscopic retrograde cholangiopancreatography (ERCP) is assumed to be a standard clinical application of intraductal injection. In ERCP, which is used for diagnosing diseases in the pancreas and bile ducts, an endoscope is inserted from the mouth to the duodenum, followed by inserting a cannula into the main pancreatic duct, injecting a contrast agent, and taking an X-ray picture. Using an endoscope, it would be possible to administer a drug solution locally to the pancreas by imitating intraductal injection without causing any damage to the common bile duct. However, the subclinical pancreatitis commonly occurs after ERCP and involves an increase in pancreatic duct pressures. In 1-2\% of cases, acute 
pancreatitis that requires medical treatment occurs. Therefore, we conclude that ERCP might be a suitable technique for gene transfer to pancreatic islets, although optimizing the conditions for this, including the injection volume and speed, is required for clinical use.

In this study, we examined the issue of whether intraductal injection could be used to achieve gene delivery to the pancreatic islets, the final target. As shown in Figure 5c, agarose gel electrophoresis detected luciferase mRNA in the islets following intraductal injection. This result suggests that the pDNA administered via the bile duct could reach the islets. While, it would be difficult to add islet selectivity to pDNA delivery via intraductal injection, because the pDNA flowing through the main pancreatic duct reaches the exocrine cell group earlier than the pancreatic islets. The results shown in Figure 5c are thought to be due to the random arrival of pDNA to the pancreatic islets where the entire pancreas is filled with the pDNA. As described above, Wang et al. reported on the successful selective gene expression in pancreatic $\beta$ cells using AAV and an insulin promoter ${ }^{6}$. Thus, even in the case of the intraductal injection of naked pDNA, this insulin promoter system could contribute to selective gene expression in pancreatic $\beta$ cells via intraductal injection. In the future, we plan to observe the localization of pDNA and protein expressed in pancreas tissue, although we are not currently able to perform this at present.

The focus of this study was on validating transgene expression in the pancreas via the intraductal delivery of naked pDNA. Therefore, we designed a protocol to evaluate gene expression at the time when gene expression is the highest. Previous studies reported that gene expression peaked within 24 hours after hydrodynamic injection for gene delivery ${ }^{14,17}$. Moreover, we observed the highest transgene expression in the pancreas at $24 \mathrm{hr}$ after intraductal injection at 3, 6, 12 and $24 \mathrm{hr}$ after administration (data not shown). Thus, we evaluated transgene expression at $24 \mathrm{hr}$ after administration in this study. While, the duration of transgene expression is a very important factor for its use in clinical applications, we conclude that evaluating transgene expression as a function of time is an important research issue for a future subject. 


\section{CONCLUSION}

We validated the possibility of the intraductal injection of pDNA for in vivo transgene expression in the pancreas. Our results indicate that gene expression activities were observed in the pancreas by intraductal injection, and the value was the highest in the pancreas, compared to all other tissues. Reverse transcription PCR analysis suggests that the pDNA that was delivered by intraductal injection was localized, not only in the pancreas but also in islets. Moreover, no injuries to the liver, the common bile duct, the pancreas were observed over time after injection, although transient injuries were observed. These findings indicate that the intraductal injection of naked pDNA promises to be a useful technique for in vivo gene delivery targeted to pancreatic tissue and islets.

\section{ACKNOWLEDGMENT}

This work was supported founded by the Kowa Life Science Foundation (to Y.Y.), and in part by a Grantin-Aid for Scientific Research (B) from the Ministry of Education, Culture, Sports, Science and Technology, the Japanese Government (MEXT). We are grateful to Dr. Jun Yamauchi for her helpful comments. We thank Oriental Yeast Co., Ltd., for the evaluation of the toxicity (Shiga, Japan). We also thank Dr. Milton Feather for his helpful advice in writing the manuscript.

\section{CONFLICTS OF INTEREST}

The authors declare no conflict of interest associated with this manuscript. 


\section{REFERENCES.}

1. Pearson ER 2008. Recent advances in the genetics of diabetes. Primary care diabetes 2(2):67-72.

2. Bell GI, Polonsky KS 2001. Diabetes mellitus and genetically programmed defects in beta-cell function. Nature 414(6865):788-791.

3. Chen S, Ding JH, Bekeredjian R, Yang BZ, Shohet RV, Johnston SA, Hohmeier HE, Newgard $\mathrm{CB}$, Grayburn PA 2006. Efficient gene delivery to pancreatic islets with ultrasonic microbubble destruction technology. Proc Natl Acad Sci U S A 103(22):8469-8474.

4. Sato M, Inada E, Saitoh I, Ohtsuka M, Nakamura S, Sakurai T, Watanabe S 2013. Site-targeted non-viral gene delivery by direct DNA injection into the pancreatic parenchyma and subsequent in vivo electroporation in mice. Biotechnol J 8(11):1355-1361.

5. Rehman KK, Trucco M, Wang Z, Xiao X, Robbins PD 2008. AAV8-mediated gene transfer of interleukin-4 to endogenous beta-cells prevents the onset of diabetes in NOD mice. Mol Ther 16(8):14091416.

6. Wang Z, Zhu T, Rehman KK, Bertera S, Zhang J, Chen C, Papworth G, Watkins S, Trucco M, Robbins PD, Li J, Xiao X 2006. Widespread and stable pancreatic gene transfer by adeno-associated virus vectors via different routes. Diabetes 55(4):875-884.

7. Cullis PR, Hope MJ 2017. Lipid Nanoparticle Systems for Enabling Gene Therapies. Mol Ther.

8. Itaka K, Kataoka K 2011. Progress and prospects of polyplex nanomicelles for plasmid DNA delivery. Current gene therapy 11(6):457-465.

9. Yokoo T, Kamimura K, Abe H, Kobayashi Y, Kanefuji T, Ogawa K, Goto R, Oda M, Suda T, Terai S 2016. Liver-targeted hydrodynamic gene therapy: Recent advances in the technique. World J Gastroenterol 22(40):8862-8868.

10. Sato Y, Sakurai Y, Kajimoto K, Nakamura T, Yamada Y, Akita H, Harashima H 2017. Innovative Technologies in Nanomedicines: From Passive Targeting to Active Targeting/From Controlled Pharmacokinetics to Controlled Intracellular Pharmacokinetics. Macromolecular bioscience 17(1).

11. Suda T, Liu D 2007. Hydrodynamic gene delivery: its principles and applications. Mol Ther 15(12):2063-2069.

12. Kobayashi N, Nishikawa M, Takakura Y 2005. The hydrodynamics-based procedure for controlling the pharmacokinetics of gene medicines at whole body, organ and cellular levels. Adv Drug Deliv Rev 57(5):713-731.

13. Bonamassa B, Hai L, Liu D 2011. Hydrodynamic gene delivery and its applications in pharmaceutical research. Pharmaceutical research 28(4):694-701.

14. Liu F, Song Y, Liu D 1999. Hydrodynamics-based transfection in animals by systemic administration of plasmid DNA. Gene Ther 6(7):1258-1266.

15. Hagstrom JE, Hegge J, Zhang G, Noble M, Budker V, Lewis DL, Herweijer H, Wolff JA 2004. A facile nonviral method for delivering genes and siRNAs to skeletal muscle of mammalian limbs. Mol Ther 10(2):386-398.

16. Yasuzaki Y, Yamada Y, Ishikawa T, Harashima H 2015. Validation of Mitochondrial Gene Delivery in Liver and Skeletal Muscle via Hydrodynamic Injection Using an Artificial Mitochondrial Reporter DNA Vector. Mol Pharm 12(12):4311-4320.

17. Ochiai H, Fujimuro M, Yokosawa H, Harashima H, Kamiya H 2007. Transient activation of transgene expression by hydrodynamics-based injection may cause rapid decrease in plasmid DNA expression. Gene Ther 14(15):1152-1159. 


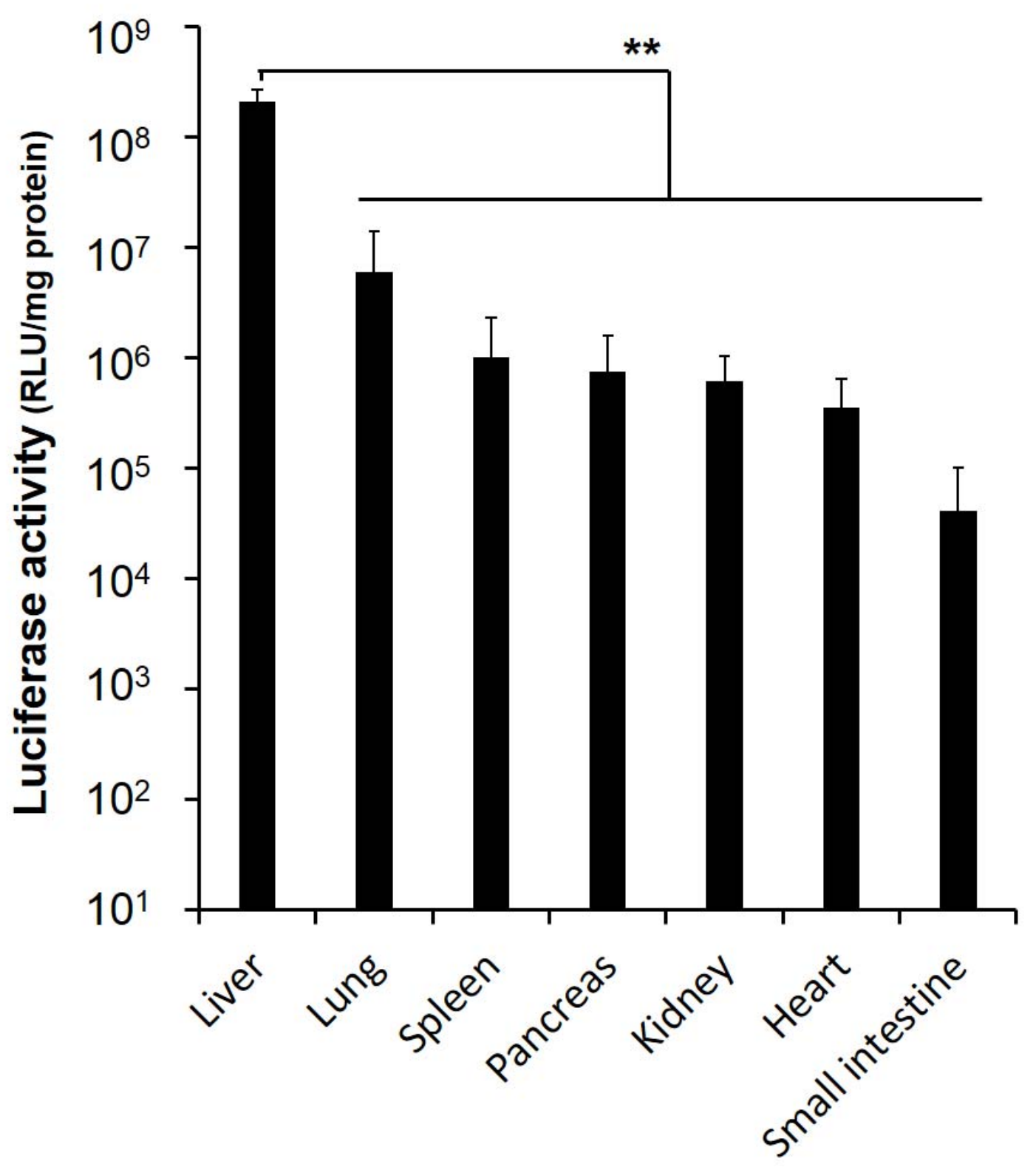

Figure 1. Gene expression in various tissues following hydrodynamic tail vein (HTV) injection. A $50 \mu \mathrm{g}$ quantity of pDNA coding luciferase was administered to the tail vein of mice via HTV injection, and the mice were sacrificed at $8 \mathrm{hr}$ post injection. The tissues including liver, spleen, kidney, lung, heart, pancreas and small intestine were then harvested, and the luciferase activities were measured. Bars indicate the means \pm S.D. $(n=3)$. **Significant differences between liver and others were calculated by one-way ANOVA, followed by Bonferroni test $(\mathrm{p}<0.01)$. 


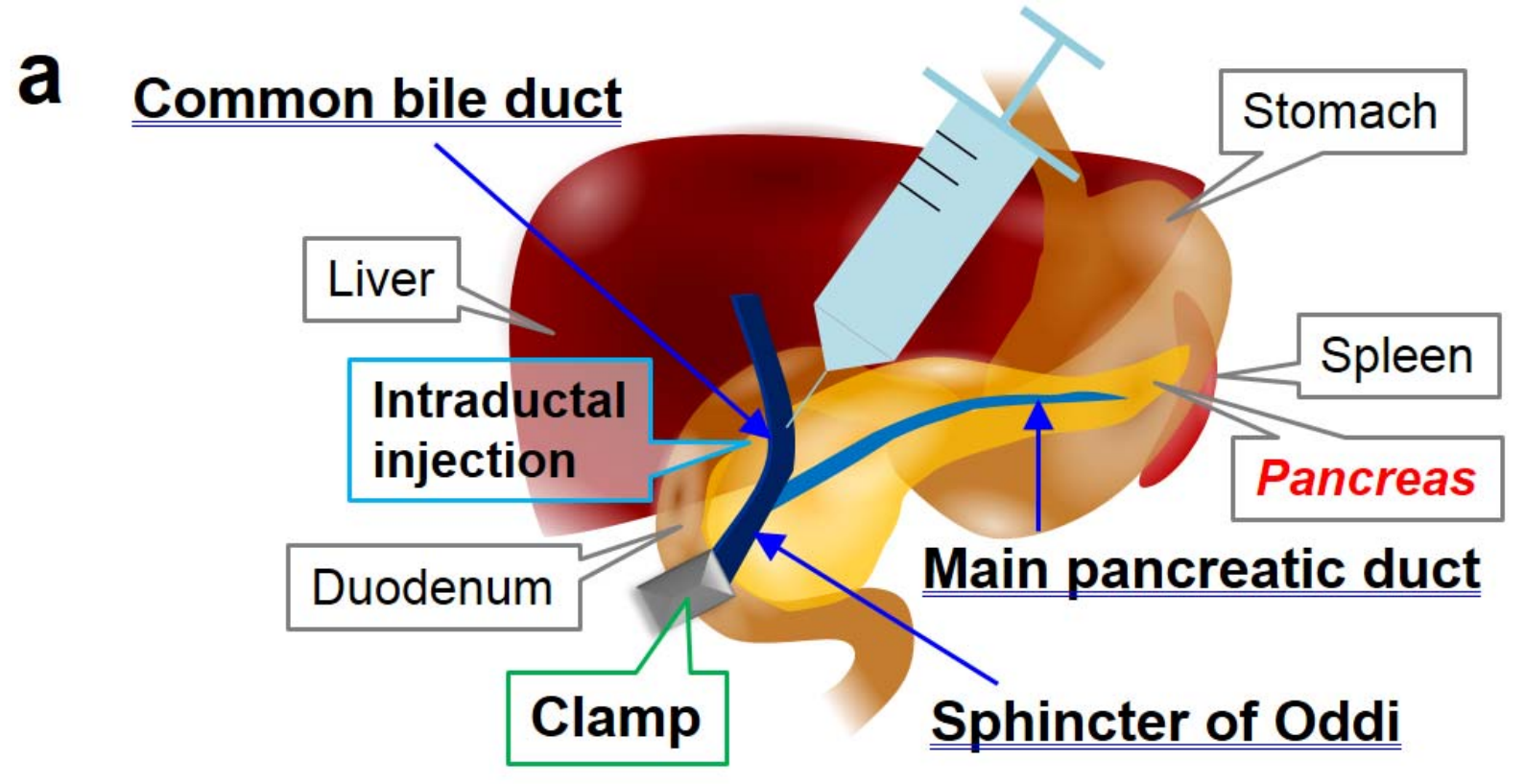

b
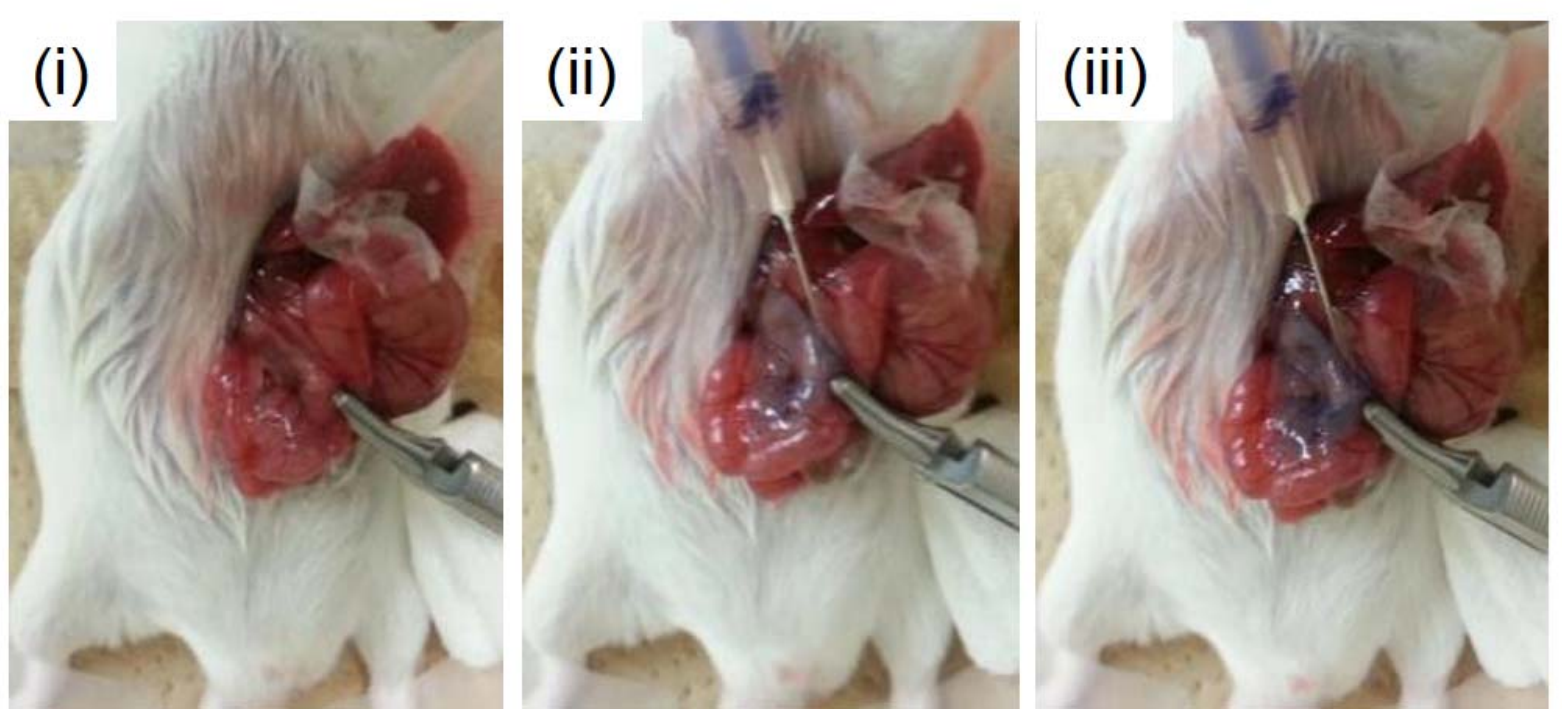

Figure 2. Schematic images of gene delivery to the pancreas by intraductal injection and observation of the distribution of the injected solution in the pancreas. (a) Schematic diagram of intraductal injection of pDNA into common bile duct of mice. A 27-gauge needle was inserted into the common bile duct and the pDNA solution was injected under conditions where the sphincter of Oddi was clamped. After the injection, the opening of the duct was sealed with a medical adhesive. (b) The distribution of the injected solution after intraductal injection of trypan blue solution. (i), non injected mouse; (ii), $50 \mu \mathrm{L}$ solution injected mouse; (iii), $100 \mu \mathrm{L}$ solution injected mouse. 
a

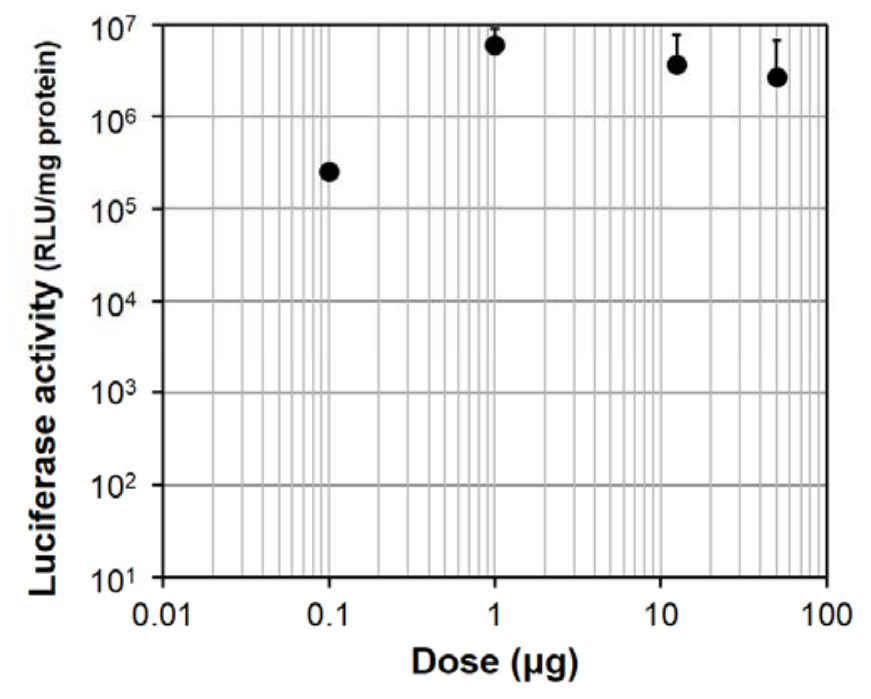

b

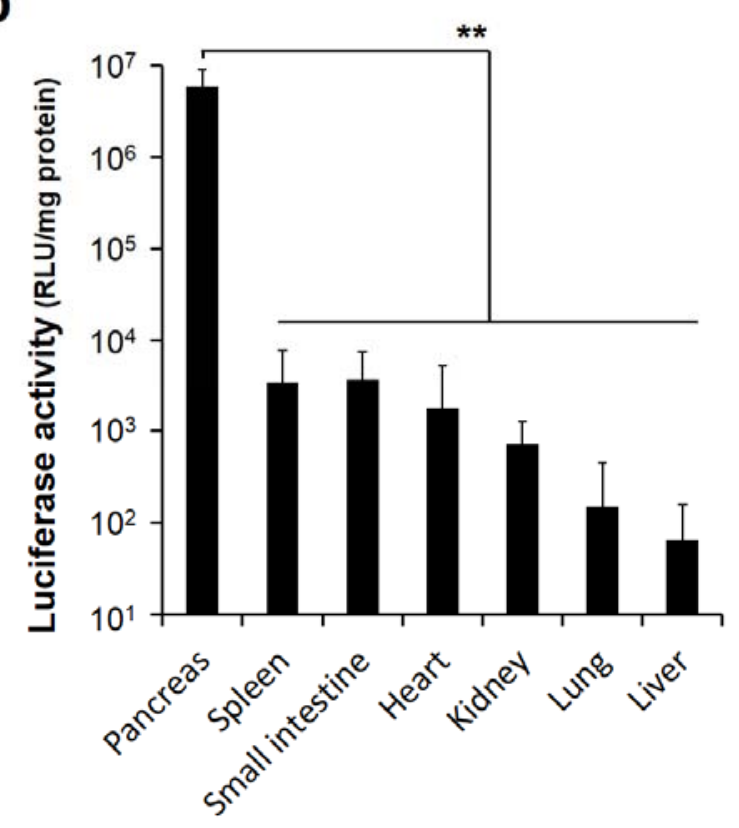

Figure 3. Investigation of gene expression in the pancreas and various tissues following the intraductal injection of naked pDNA. (a) Various amounts of pDNA coding luciferase $(0.1,1,12.5$ or $50 \mu \mathrm{g}$ ) in 50 $\mu \mathrm{L}$ saline were injected in $5 \mathrm{sec}$ through the common bile duct. The pancreas was harvested at $24 \mathrm{hr}$ after injection, and the luciferase activities were evaluated. Data are expressed as the mean \pm S.D. ( $\mathrm{n}=3)$. (b) After intraductal injection of $1 \mu \mathrm{g}$ pDNA in $50 \mu \mathrm{L}$ saline in $5 \mathrm{sec}$, the tissues including liver, spleen, kidney, lung, heart, pancreas and small intestine were harvested at $24 \mathrm{hr}$ post injection, and luciferase activities were measured. Bars indicate the means \pm S.D. $(\mathrm{n}=3)$. **Significant differences between pancreas and others were calculated by one-way ANOVA, followed by Bonferroni test $(p<0.01)$. 
a

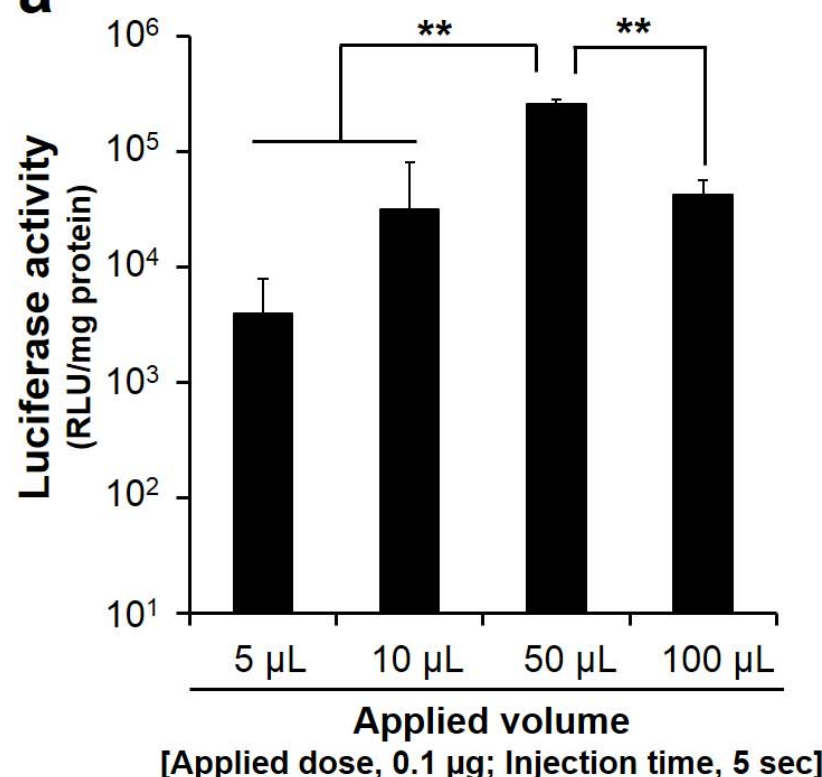

b

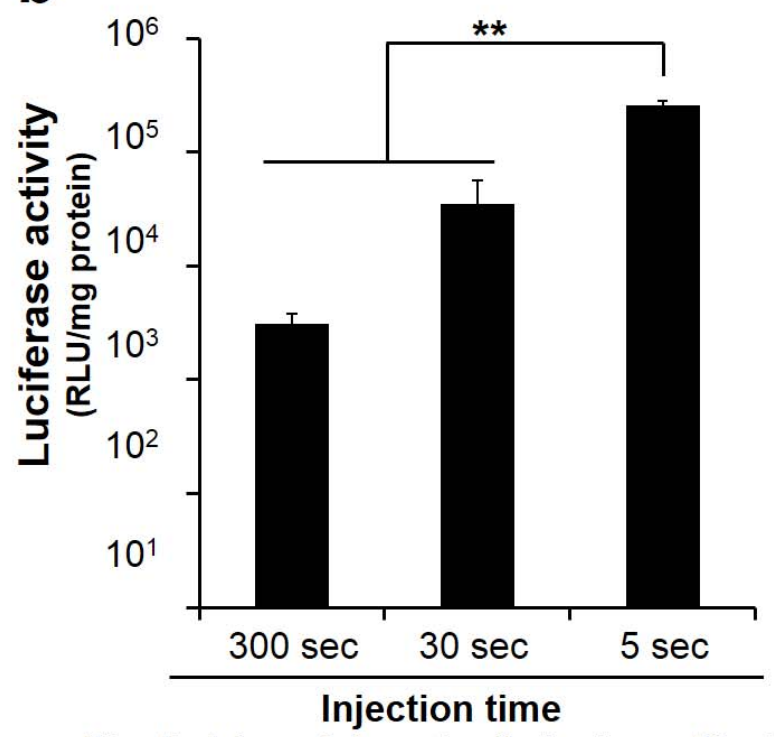

[Applied dose, $0.1 \mu \mathrm{g}$; Applied volume, $50 \mu \mathrm{L}$ ]

Figure 4. Effects of applied volume (a) and injection time (b) on pancreas gene expression by the injection of pDNA through the common bile duct. At $24 \mathrm{hr}$ after the intraductal injection of $0.1 \mu \mathrm{g}$ pDNA under various conditions, the pancreas was harvested and the luciferase activities measured. Bars indicate the means \pm S.D. $(n=3) . * *$ Significant differences were calculated by one-way ANOVA, followed by SNK test $(\mathrm{p}<0.01)$. 


\section{a}

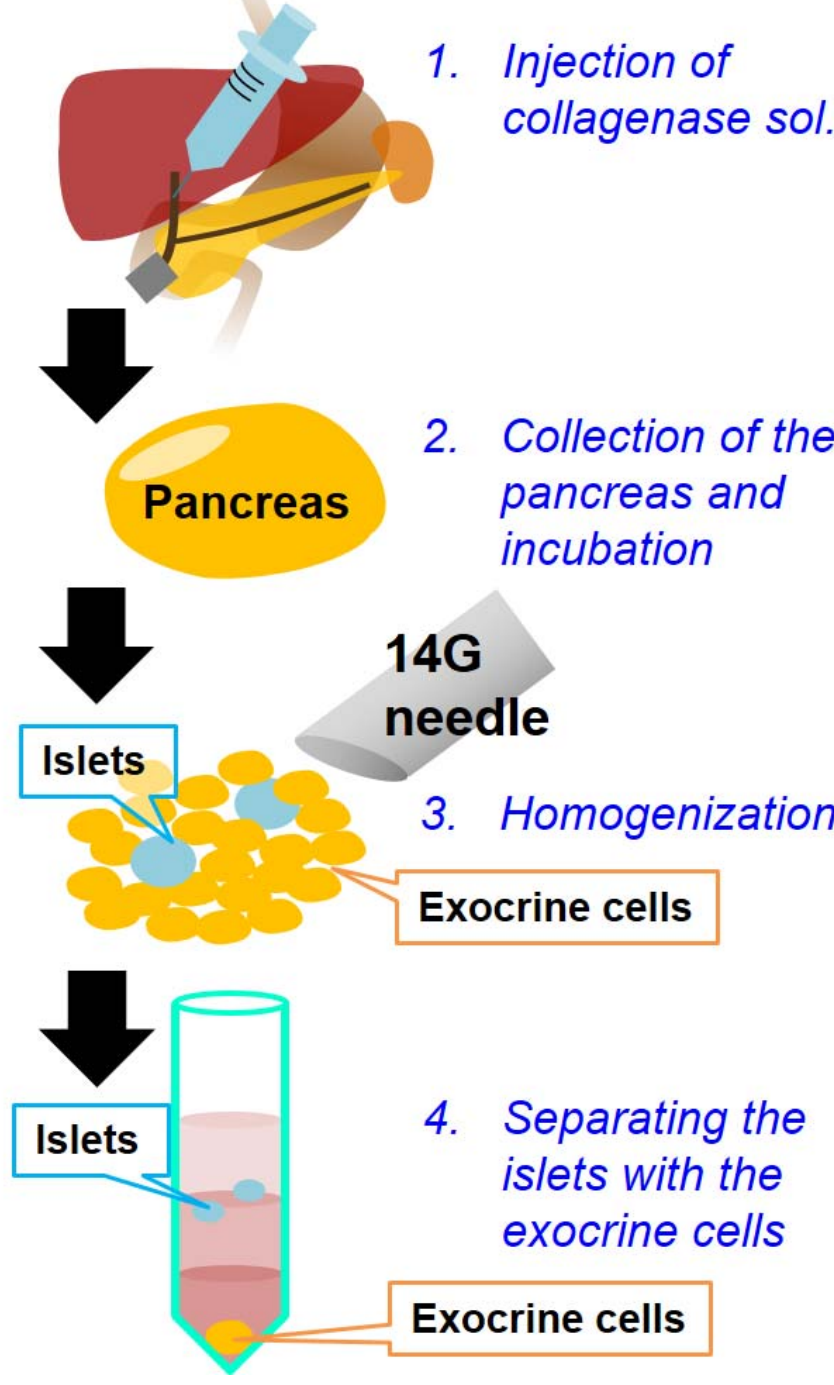

b

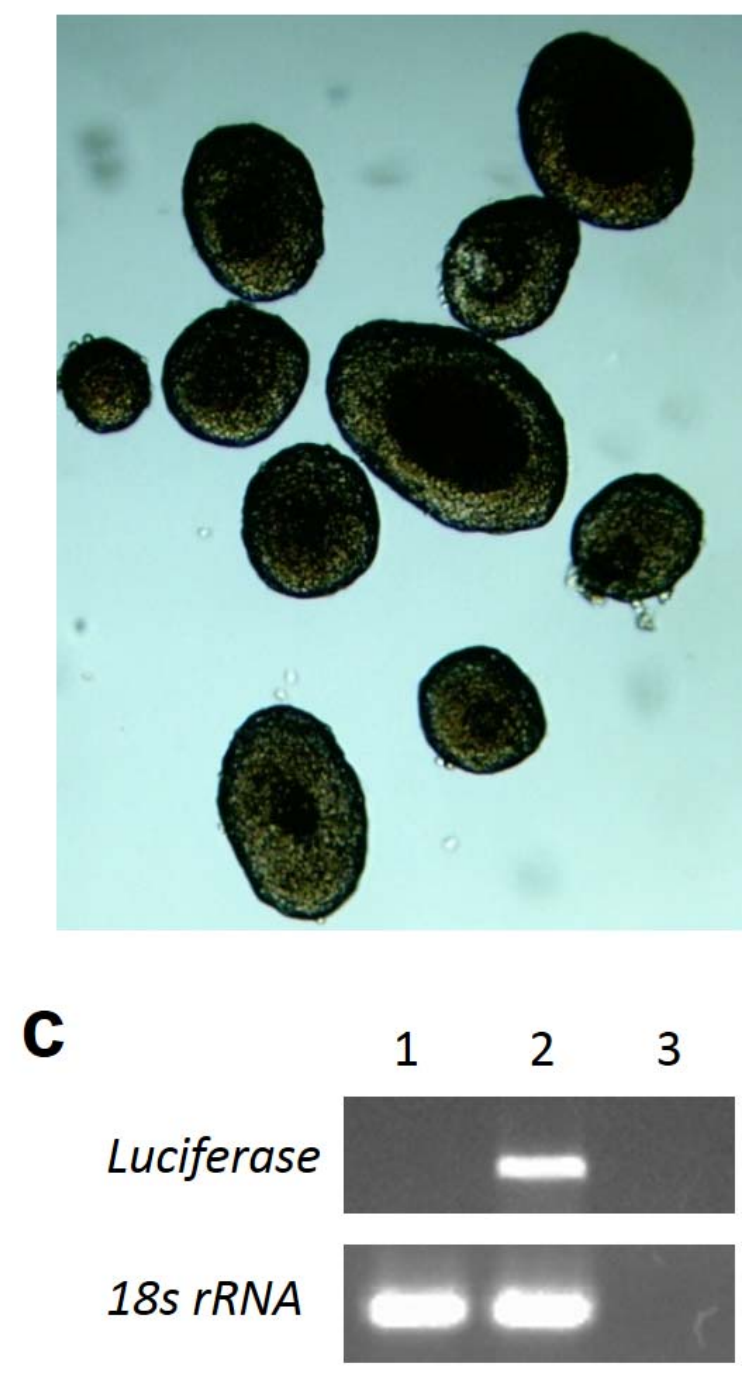

Figure 5. Validation of gene delivery to pancreatic islets via intraductal injection. (a) Schematic diagram of islets isolation from mouse pancreas. The sphincter of Oddi was clamped and 7-8 $\mathrm{mL}$ of a $2 \mathrm{mg} / \mathrm{mL}$ type IV collagenase solution was injected (1). The pancreas was harvested and incubated at $37^{\circ} \mathrm{C}$ for 13 min (2). The tissue was homogenized with a 14-gauge needle (3). The islets and exocrine cells were separated by sucrose density-gradient centrifugation (4). (b) Image of isolated islets observed by microscopy. Detection of luciferase mRNA in the pancreatic islet (c). Total RNA was extracted from the islets $24 \mathrm{hr}$ after pDNA injection and RT-PCR was performed. Lane 1, control pDNA (non-encoding luciferase) injection, RT (+). Lane 2, luciferase coding pDNA injection, RT (+). Lane 3, luciferase coding pDNA injection, RT (-). 

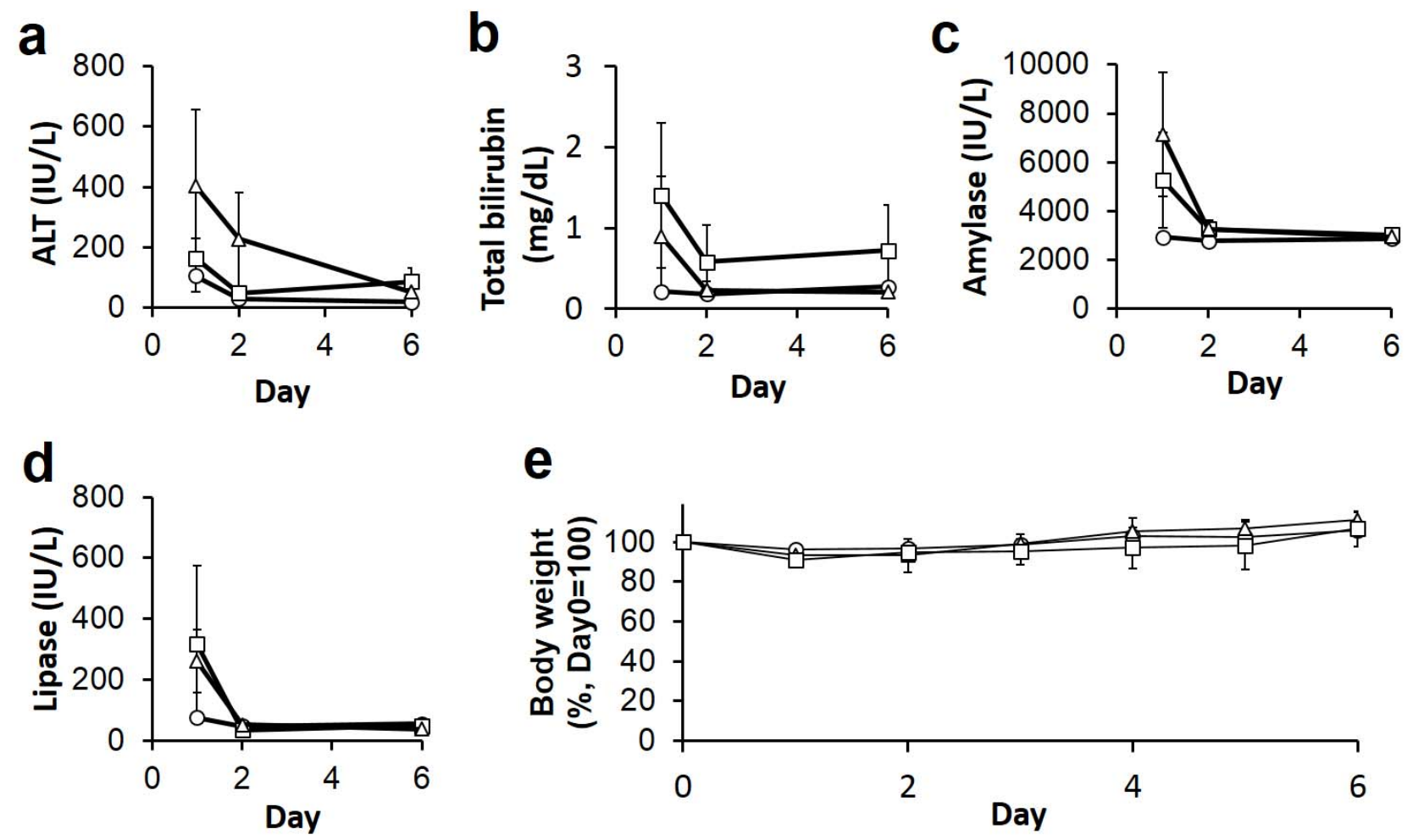

Figure 6. Investigation of injury following intraductal injection. Serum was collected 1, 2, 6 days after pDNA administration via intraductal injection of $1 \mu \mathrm{g}$ pDNA in $50 \mu \mathrm{L}$ saline in $5 \mathrm{sec}$. The concentrations of ALT (a), total bilirubin (b), amylase (c), and lipase (d) were then measured. Body weight of mice was also measured (e). Circles, non-treated mice; squares. sham treated mice; triangles; pDNA injected mice. 